\title{
VALIDATION OF THE CHILD -ORAL IMPACTS ON DAILY PERFORMANCES QUESTIONNAIRE AMONG GROUP OF11-12YEAR-OLD EGYPTIAN CHILDREN
}

\author{
Mona E. Zaghloul' ${ }^{1} B D S$, Hala A. Amer' $P h D$, Amel M. Ahmed ${ }^{3} P h D$
}

\begin{abstract}
INTRODUCTION: Oral health related quality of life measure has a great importance at all levels of dental research, it helps to plan evidence based public health policies and indicates how resource allocation should be done.

OBJECTIVES: The aim of this study was to assess the Child-OIDPQ reliability and validity for application among Egyptian children aged 11-12-year-old, as well as determining the prevalence and causes of oral impacts on daily performances in public and private school children in Alexandria.

MATERIALS AND METHODS: Cross-sectional survey performed on 410 randomly selected student aged 11-12 years in the middle district of Alexandria city, Egypt. Data were collected through a self-administered questionnaire; Child-Oral Impacts on Daily Performances questionnaire (Child-OIDP).

RESULTS: The instrument showed acceptable psychometric properties and is considered as a valid, reliable and practical inventory for use among the Egyptian sample. (Cronbach's alpha 0.71 for severity and 0.70 for frequency). The prevalence of oral impacts was high (85.4 \%) of children experiencing some kind of oral conditions affecting their daily life during the past three months. The highest impact was reported on eating (61.9\%) followed by cleaning (46.3\%) and the lowest impact was on speaking $(21.0 \%)$. Tooth pain was one of the main perceived causes of impacts on the following 5 performances: duties (35.9\%), emotional status (11.1\%), sleeping (42.2\%), eating (32.0\%) and speaking $(16.7 \%)$. there was no statistically significant difference detected by Mont Carlo exact probability test in the intensity effect of impact between public and private schools
\end{abstract}

CONCLUSIONS: It was concluded that the Child-OIDP questionnaire can be applied to Egyptian children as a valid measure of oral health related quality of life.

KEYWORDS: oral health; C-OIDP; validity; quality of life

1-Bachelor of Dentistry, Faculty of Dentistry, Alexandria University, Alexandria, Egypt.

2-Professor of Pediatric Dentistry, Faculty of Dentistry, Alexandria University, Alexandria, Egypt.

3- Associate Professor of Pediatric Dentistry, Faculty of Dentistry, Alexandria University, Alexandria, Egypt.

Corresponding author:

E-mail: monazaghloul44@yahoo.com

\section{INTRODUCTION}

The most famous modern definition of health was created by the World Health Organization to be physical, emotional, and social wellbeing, and not merely the absence of disease or infirmity, while the Ottawa charter for health promotion (WHO, 1986) states that, in order to be healthy, an individual or group must be able to identify and to realize aspirations, to satisfy needs, and to change or cope with the environment $(1,2)$.

In recent years, great attention has been focused on the effect of poor oral health, not only on general health but also on people day-to-day functioning, and ability to carry out activities of daily living. Therefore, the concept of oral health-related quality of life (OHRQOL) attracted increasing interest over the last

decades and became important for many researchers who are focusing on the impact of oral diseases on different aspects of life (3-5).

Oral health related quality of life has a great importance at all levels of dental research; it helps to plan evidence based public health policies and indicates how resource allocation should be done .Clinically; it may assist in screening and monitoring for psychosocial problems and outcomes of care, but it is important to know that health problems do not always affect the individuals' perception of their QoL, a lot of people who suffer from chronic health problems often rate their QoL higher than healthy individuals (6-8).
In a WHO report (2003), it was concluded that the social impact of oral diseases results in restricted school work, home activities and loss of millions of school and work hours annually (9). On the other hand, researches showed that dental treatment makes a very significant difference to the psychological and social aspects of the child's life, these improvements include less pain and improved abilities to eat and sleep (10-12). Most of the studies assessing the impact of dental caries on the (OHRQoL) for children and adolescents have reported significant associations (13-15). In 2015, Paula et al evaluated the associations of subjective perceptions of parents, socio-economic factors, and oral clinical conditions of children with their school performance; he was found that the schoolchildren who had carious lesions and underwent curative dental treatment at the beginning of the academic year, reported 1.5 more chance of having low performance compared with schoolchildren who had no caries lesions (16).

In the field of dental research, five instruments were designed to assess the OHRQoL among children specifically; however, those most frequently self-completed by children were the Child Perceptions Questionnaire (CPQ), the Child Oral Impacts on Daily Performances (COIDPQ) and the Child Oral Health Impact Profile (COHIP) (17).

The Child-OIDP is advantageous for use in assessing oral health needs in population surveys, not only because it is 
easy, but also for being short (17). It has also been used in cross-sectional surveys with the aim to discriminate between different groups (18). The C-OIDPQ was initially developed (in English) in Thailand (19) and has shown to be valid and reliable when applied to the children in the United Kingdom (20), France (21), Brazil (22), Spain (23), Thailand (24) and Italy (25).

The current study aimed to carry out a cross-cultural adaptation of the Child-OIDPQ and to assess its reliability and validity for application among Egyptian children aged 11-12 year-old, and to determine the prevalence and causes of oral impacts on daily performances in public and private school children in Alexandria.

This study is planned to test the hypothesis that the COIDPQ may or may not be a valid and sensitive instrument to measure the oral impact on daily performance among a sample of Egyptian children.

\section{MATERIALS AND METHODS}

\section{Study design and sampling procedure}

A cross sectional analytical study was performed, after securing approval from the Educational Administration of Alexandria governorate, School lists were obtained, and then a proportional allocation multistage random sample was selected. In the first stage Middle district was randomly selected from the eight districts of Alexandria by writing the names of the district in a bowel and blindly selecting one, then in the second stage five schools were randomly selected based on the number of Public and Private schools in the district, according to the determined proportion from the lists, they were 55public,40 private and 25 experimental schools which represent an intermediate type which is public paid schools .Therefore an equal number of public and private schools was selected according to the determined proportion from the lists, While because the average number of the students in the public schools is more than the private one so the selected number of the schools was planned to be two public and three private schools, after that computer selection from school lists fed to the computer was done. The third stage involved the number of students selected from each school, where all children of the sixth grade in both public and private schools were selected to fulfill the sample size

Using a power of $80 \%$ to detect the average DMFT among 11-12 year-old students with below average school performance, it was found to be $4.2+/-2.6$, with effect size $=0.3$ and Alpha error $=0.05$, design effect $=2 .(26)$; the sample size was calculated using G. Power software (27). The minimal sample size was found to be 360 (was rounded to400). However, in some of the randomly selected schools or classes, the desired number of children was not available, while in others refusal to participate of some children reduced the sample size, therefore extra children were chosen from other classes to compensate for the deficiency.

From all children, (attending school on the day of clinical examination) of both genders, aged 11-12 year-old and in the 6th year final primary school, 410 children were included in the study, after excluding those who had systemic diseases or showed any signs of physical disabilities, as well as those who were not ready to give the consent to participate in the study or refused to fill the questionnaire and those who were uncooperative during clinical examination.
Ethical 0approval for the study first obtained from Dental Research Ethics Committee, Faculty of Dentistry) Alexandria University (.

The school administration was responsible of informing both parents and students about the study, and a day was set for each school to perform the examination and fill the questionnaire. The children provided their consent on the examination sheet.

Oral impact on daily performance Questionnaire survey and measures

Personal data were collected from each child using a selfadministered questionnaire after reading and explaining the questions in a non-leading language, the students had the opportunity to ask clarifying questions regarding the survey, the researcher oversaw that all questions were properly completed.

Oral health-related quality of life was measured using an Arabic version of the (Child-OIDP) questionnaire. The original form of the (Child-OIDP) questionnaire that was constructed in English was translated into Arabic by specialist translator and back to English by different translator. The two English versions were then compared by the professor of pediatric dentistry in the faculty department.

The Child-OIDP questionnaire started with asking if they have experienced common oral problems during the previous 3 months. Each question was answered (1) yes or (0) no to the following oral conditions: toothache, sensitive teeth, tooth decay (hole in teeth), exfoliating primary teeth, tooth space (due to a non-erupted permanent tooth), fractured permanent tooth, color, shape or size of the teeth, position of teeth, bleeding gum, swollen gum, calculus, oral ulcers, bad breath, deformity of the mouth or face, erupting permanent tooth and missing permanent tooth $(20,24,25)$. Then data were collected regarding the effects of oral problems on eight common daily performances, namely eating, speaking, and cleaning mouth, sleeping, smiling, school work and emotion. If the child responded positively, he/she had to respond to questions about the severity and frequency of the specific impact; a score from 0 to 3 was given to rate each of these characteristics. When no impact was reported, the child was received score of zero.

The calculation of the index involved performance score (PS) which was the product of the multiplication of severity (range between 0-3) and frequency (range between 0-3), PS (range between 0-9), Child-OIDP simple count score (Child-OIDP-SC) or Extent (range between 0-8) refers to the number of performances with impacts (PWI) affecting a child's quality of life in the past 3 months. An alternative method of reporting the severity of oral impacts from the same data set was to use the 'intensity' and 'extent' of impacts, where the intensity refers to the most severe impacts on any of the 8 performances or the highest performance score. It is classified into 6 levels; none, very little, little, moderate, severe and very severe, (Table 1) 
Table 1: Classification of the intensity of oral impacts on a performance

\begin{tabular}{|c|c|c|c|c|}
\hline \multirow{2}{*}{$\begin{array}{c}\text { The } \\
\text { intensity of } \\
\text { impacts }\end{array}$} & \multirow{2}{*}{$\begin{array}{c}\begin{array}{c}\text { Severity } \\
\text { score }\end{array} \\
\text { Severe (3) }\end{array}$} & \multicolumn{2}{|c|}{$\begin{array}{c}\text { Frequency } \\
\text { score }\end{array}$} & \multirow{2}{*}{$\begin{array}{c}\begin{array}{c}\text { Performance } \\
\text { score }\end{array} \\
9\end{array}$} \\
\hline & & $\mathbf{x}$ & $\begin{array}{l}\text { Severe } \\
\text { (3) }\end{array}$ & \\
\hline \multirow[t]{2}{*}{ Severe } & Severe (3) & $\mathrm{x}$ & $\begin{array}{l}\text { Moderate } \\
\text { (2) }\end{array}$ & \multirow[t]{2}{*}{6} \\
\hline & $\begin{array}{l}\text { Moderate } \\
\text { (2) }\end{array}$ & $\mathrm{x}$ & $\begin{array}{l}\text { Severe } \\
\text { (3) }\end{array}$ & \\
\hline \multirow{3}{*}{ Moderate } & $\begin{array}{c}\text { Moderate } \\
\text { (2) }\end{array}$ & $x$ & $\begin{array}{c}\text { Moderate } \\
\text { (2) }\end{array}$ & 4 \\
\hline & Severe (3) & $x$ & Little (1) & \multirow[b]{2}{*}{3} \\
\hline & Little (1) & $\mathrm{x}$ & $\begin{array}{l}\text { Severe } \\
(3)\end{array}$ & \\
\hline \multirow{2}{*}{ Little } & $\begin{array}{l}\text { Moderate } \\
\text { (2) }\end{array}$ & $x$ & Little (1) & \multirow{2}{*}{2} \\
\hline & Little (1) & $\mathrm{x}$ & $\begin{array}{l}\text { Moderate } \\
\text { (2) }\end{array}$ & \\
\hline Very little & Little (1) & $x$ & Little (1) & 1 \\
\hline
\end{tabular}

following the alternative Scoring method described by Gherungpong et al (24).

The idea behind this is to differentiate between for example, a child with minor impacts (score of 1) on 6 performances and another child with severe impacts (score of 6) on only 1 performance. In the former case, the child will be in the 'very little', and in the latter one, in the 'severe' category.

\section{Validity and reliability of the questionnaire}

A pilot study was conducted to test the validity of the Child Arabic version of the Child Oral Impact on Daily Performance (Child-OIDP) questionnaire on a child sample in Alexandria, Egypt and to determine the time necessary for completion of the interview. It was tested on two successive occasions on the same group of children to assess the reliability of responses.

\section{Statistical analyses}

After data were collected it was revised, coded and fed to statistical software IBM SPSS version 20. The given graphs were constructed using Microsoft excel software.

All statistical analysis was done using two tailed tests and alpha error of 0.05 . $P$ value less than 0.05 was considered to be statistically significant.

The following statistical tests were used:

A. Descriptive statistics: included the mean with standard deviation for the numeric data while percent was used to describe the frequency of each category for categorical data. Regarding skewed data (with outliers), median with range were used.

B. Analysis of numeric data

One-Sample Kolmogorov-Smirnov Test: a procedure compares the observed cumulative distribution function for a variable with a specified theoretical distribution which was the normal distribution at the current data (testing for distributional assumption for numerical data) then the following statistical analysis was done:

a. Independent sample t-test: it is a parametric statistical test that is used to compare the mean for numeric variables (severity scores) between two independent groups (schools or grades) Man Whitney test: a procedure compares ranks (medians of DMF) for two independent groups (schools or grades) of the study. it is like t-test but with skewed data. if the variable follows normal distribution.

b. Man Whitney test: is a procedure that compares ranks (medians of DMF) for two independent groups (schools or grades) of the study, similar to t-test but is used in case of skewed data.

C. Analysis of categorical data

Mont Carlo exact test and Fishers exact test: they are alternatives for the Pearson's chi square test to test for differences at frequencies between different schools at different measured parameters.

\section{RESULTS}

Since the Child- OIDP questionnaire was used in the present study for the first time in Egypt, it was necessary to test its psychometric properties, the psychometric testing involved the assessment of internal and test-retest reliability in addition to face and content validity (28).

Validity of the Child-OIDP Questionnaire was established prior to the main study. During the pilot study, the Child-OIDP questions were administered to a randomly selected schoolchildren sample of 20 children then reintroduced to the same sample with a 10-day-interim Period.

Face validity refers to whether the items appear to be measuring what they are supposed to measure or not. All schoolchildren completed the child-OIDP questionnaire providing support for its face validity, face and Content validity of the Child-OIDP was measured by the interaction and understanding of the questionnaire during the pilot study and confirmed through a discussion with the children and their teachers (29).

As a result, very minor changes were provided to the questionnaire prior to the main study. The experience of the professors of pediatric dentistry in the faculty department, who knew the terms used by children when referring to oral health and problems, was important for the modification process. The modifications did not affect the content of the index but aimed to facilitate comprehension and ease of administration in the culturally specific context, these modifications were like changing Sensitive tooth in the original questionnaire into Sensitive teeth (when you eat or drink: sweets, hot food such as milk or cold such as ice cream), Color of tooth was changed into Color of tooth (darker or more yellow in color, or has patches and stained).

Test Retest Reliability for severity of problem and frequency of effect, which were measured by the intra class correlation (ICC) were 0.886 and 0.837 respectively.

The internal consistency analysis resulted in a standardized Cronbach's alpha of (0.714) for the severity of the problem, and (0.703) for the frequency of effect. Therefore, from the obtained data, the questionnaire with this Arabic version was proved to be a valid and reliable measure to be used in Egypt on school children.

Descriptive data of study participants Figure (1) shows the socio-demographic of the study participants. After concerning the exclusion criteria, this resulted in a final sample size of 410 children with response rate of 78.6 , distributed as 249 children from private schools (60.7\%) and 161 children from public schools (39.7\%). Relative to gender distribution there were 206 (50.2\%) girls and 204 (49.8\%) boys in the sample. The highest percentage of their fathers were in professional work (69.3), about (30.7) were 
manual workers while (67.6 \%) of mothers were housewife.

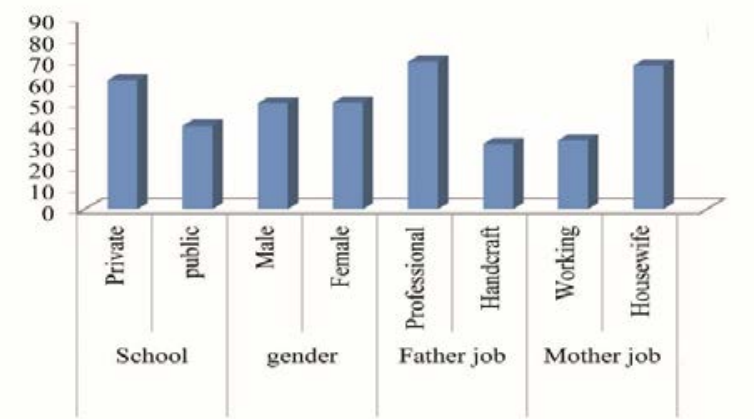

Figure (1): The socio-demographic characteristics of the study participants.

The studied sample showed high levels of perceived oral problems; where about $96.4 \%$ of the children reported at least one problem. On the other hand, 3.6\% had no problems. About $21.8 \%$ had $1-2$ problems, while the percentage of 3-5 problems and more than 6 problems was the same $37.3 \%$. Figure (2) describes the prevalence and types of perceived oral problems among the study participants. The most frequently reported oral problem was sensitive teeth (48.6\%) followed by tooth pain $(44.3 \%)$, while the least reported problems were broken teeth and orofacial deformity (13.7\%), (4.1\%) respectively.

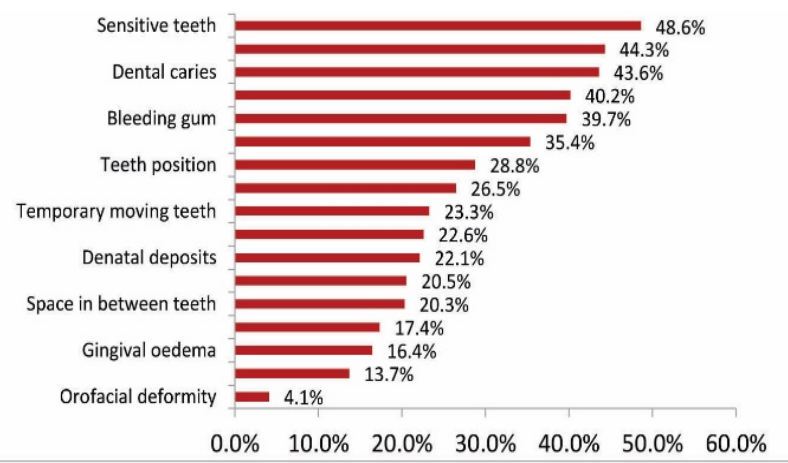

Figure (2): The prevalence and types of perceived oral problems among the study participants.

\section{Prevalence, extent, severity and intensity of oral impacts}

The prevalence of oral impacts on the present sample was high, $85.4 \%$ of children were experiencing some kind of oral impact on their daily life during the past three months. Among the children with impacts, the extent of impacts varied from 1 to 8 performances with impacts (PWI), where $42.0 \%$ had 1-2 PWI, $24.0 \%$ had 3-5, and $19.4 \%$ had 6-8 PWIs.

Figure (3) illustrates the prevalence of the types of oral impacts on daily performances, The performances with the highest frequency of impacts were "eating" (61.9\%), "cleaning mouth" (46.3\%), "smiling" (39.0\%), "emotional status" (34.7\%), 'sleep'” and' communication” (29.2\%) while the performance with the lowest impact was' 'duties" (26.5\%)and "speaking" (21.0\%). (26.5\%)and "speaking"
(21.0\%).

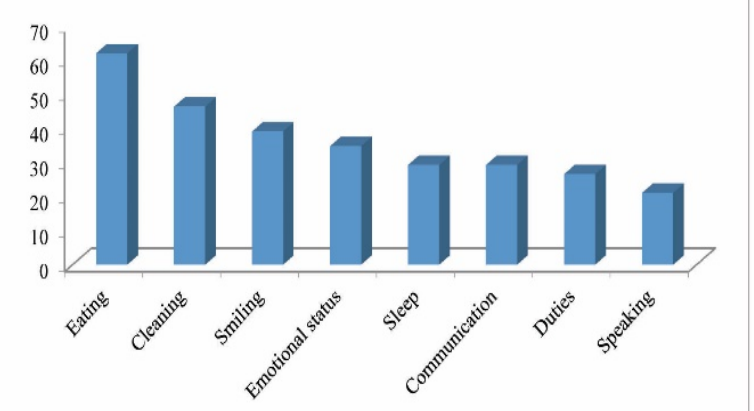

Figure (3): The prevalence of the types of oral impacts on daily performances.

Table (2) shows the oral conditions perceived as a cause of oral impacts. The majority of impacts on Eating were caused by sensitive teeth (32.2\%), while the main cause for difficulty with cleaning the mouth was bleeding gum (43.8\%), the majority of impacts on smiling were caused by teeth color change accounting for (31.0\%), emotional status "mostly affected by teeth color change reported by (19.2\%). The impact on speaking was affected by dental caries (26.2\%), while bad breath was the most frequent perceived cause of impacts on communication (44.1\%). Tooth pain was one of the main perceived causes of impacts on the following 5 performances: duties (35.9\%), emotional status (11.1\%), sleep (42.2\%), eating (32.0\%) and speak (16.7\%). 
Table (2): The oral conditions perceived as a cause of oral impacts (\%).

\begin{tabular}{|c|c|c|c|c|c|}
\hline \multirow{2}{*}{\begin{tabular}{|l} 
The performance \\
Eating \\
\end{tabular}} & \multicolumn{5}{|c|}{ The cause of impact } \\
\hline & Tooth pain & \multicolumn{2}{|l|}{ Dental caries } & \multicolumn{2}{|l|}{ Sensitive teeth } \\
\hline & $28.6 \%$ & \multicolumn{2}{|l|}{$19.2 \%$} & \multicolumn{2}{|l|}{$32.4 \%$} \\
\hline \multirow[t]{2}{*}{ Speaking } & Bad odour & Tooth pain & Tooth position & Dental caries & Spaces \\
\hline & $7.1 \%$ & $16.7 \%$ & $7.1 \%$ & $26.2 \%$ & $7.1 \%$ \\
\hline \multirow[t]{2}{*}{ Cleaning } & Tooth pain & Bleeding & Gingival edema and bleeding & Sensitive teeth & Gingivitis \\
\hline & $11.0 \%$ & $43.8 \%$ & $8.2 \%$ & $7.5 \%$ & $8.2 \%$ \\
\hline \multirow[t]{2}{*}{ Sleeping } & \multicolumn{3}{|l|}{ Tooth pain } & \multicolumn{2}{|l|}{ Dental caries } \\
\hline & \multicolumn{3}{|l|}{$42.4 \%$} & \multicolumn{2}{|l|}{$24.2 \%$} \\
\hline \multirow[t]{2}{*}{ Emotional Status } & Tooth pain & \multicolumn{2}{|l|}{ Tooth position } & \multicolumn{2}{|c|}{ Teeth color change } \\
\hline & $11.1 \%$ & $8.1 \%$ & $8.1 \%$ & \multicolumn{2}{|l|}{$19.2 \%$} \\
\hline \multirow[t]{2}{*}{ Smiling } & Bad odour & Teeth color change & Tooth shape & \multicolumn{2}{|l|}{ Curved teeth } \\
\hline & $13.8 \%$ & \multicolumn{2}{|l|}{$31.0 \%$} & \multicolumn{2}{|l|}{$8.6 \%$} \\
\hline \multirow[t]{2}{*}{ Duties } & \multicolumn{3}{|l|}{ Tooth pain } & \multicolumn{2}{|l|}{ Dental caries } \\
\hline & \multicolumn{3}{|l|}{$35.9 \%$} & \multicolumn{2}{|l|}{$25.0 \%$} \\
\hline \multirow[t]{2}{*}{ Communication } & Bad odour & \multicolumn{2}{|r|}{ Teeth color change } & \multicolumn{2}{|l|}{ Tooth shape } \\
\hline & $44.1 \%$ & \multicolumn{2}{|r|}{$11.8 \%$} & \multicolumn{2}{|l|}{$10.3 \%$} \\
\hline
\end{tabular}

Table (3) Comparison between private and public schools in the intensity of impact on the eight daily performances

\begin{tabular}{|c|c|c|c|c|c|c|c|c|}
\hline \multirow{3}{*}{ Problems } & & \multicolumn{4}{|c|}{ School } & \multirow{2}{*}{\multicolumn{2}{|c|}{ Total }} & \multirow{3}{*}{ MCP } \\
\hline & & \multicolumn{2}{|c|}{ Private } & \multicolumn{2}{|c|}{ Governmental } & & & \\
\hline & & No & $\%$ & No & $\%$ & No & $\%$ & \\
\hline \multirow{5}{*}{ Eating } & Very little & 53 & $39.0 \%$ & 42 & $36.2 \%$ & 95 & $37.7 \%$ & \multirow{5}{*}{0.430} \\
\hline & Little & 28 & $20.6 \%$ & 21 & $18.1 \%$ & 49 & $19.4 \%$ & \\
\hline & Moderate & 27 & $19.9 \%$ & 34 & $29.3 \%$ & 61 & $24.2 \%$ & \\
\hline & Severe & 16 & $11.8 \%$ & 13 & $11.2 \%$ & 29 & $11.5 \%$ & \\
\hline & Very severe & 12 & $8.8 \%$ & 6 & $5.2 \%$ & 18 & $7.1 \%$ & \\
\hline \multirow{5}{*}{ Speaking } & Very little & 16 & $32.0 \%$ & 9 & $21.4 \%$ & 25 & $27.2 \%$ & \multirow{5}{*}{0.532} \\
\hline & Little & 13 & $26.0 \%$ & 15 & $35.7 \%$ & 28 & $30.4 \%$ & \\
\hline & Moderate & 11 & $22.0 \%$ & 8 & $19.0 \%$ & 19 & $20.7 \%$ & \\
\hline & Severe & 7 & $14.0 \%$ & 9 & $21.4 \%$ & 16 & $17.4 \%$ & \\
\hline & Very severe & 3 & $6.0 \%$ & 1 & $2.4 \%$ & 4 & $4.3 \%$ & \\
\hline \multirow{5}{*}{ Cleaning } & Very little & 24 & $20.5 \%$ & 15 & $17.4 \%$ & 39 & $19.2 \%$ & \multirow{5}{*}{0.412} \\
\hline & Little & 37 & $31.6 \%$ & 28 & $32.6 \%$ & 65 & $32.0 \%$ & \\
\hline & Moderate & 34 & $29.1 \%$ & 19 & $22.1 \%$ & 53 & $26.1 \%$ & \\
\hline & Severe & 15 & $12.8 \%$ & 13 & $15.1 \%$ & 28 & $13.8 \%$ & \\
\hline & Very severe & 7 & $6.0 \%$ & 11 & $12.8 \%$ & 18 & $8.9 \%$ & \\
\hline \multirow{5}{*}{ Sleep } & Very little & 14 & $31.8 \%$ & 12 & $23.5 \%$ & 26 & $27.4 \%$ & \multirow{5}{*}{0.450} \\
\hline & Little & 10 & $22.7 \%$ & 9 & $17.6 \%$ & 19 & $20.0 \%$ & \\
\hline & Moderate & 14 & $31.8 \%$ & 20 & $39.2 \%$ & 34 & $35.8 \%$ & \\
\hline & Severe & 2 & $4.5 \%$ & 7 & $13.7 \%$ & 9 & $9.5 \%$ & \\
\hline & Very severe & 4 & $9.1 \%$ & 3 & $5.9 \%$ & 7 & $7.4 \%$ & \\
\hline \multirow{5}{*}{$\begin{array}{l}\text { Emotional } \\
\text { status }\end{array}$} & Very little & 37 & $45.7 \%$ & 20 & $28.2 \%$ & 57 & $37.5 \%$ & \multirow{5}{*}{0.223} \\
\hline & Little & 10 & $12.3 \%$ & 9 & $12.7 \%$ & 19 & $12.5 \%$ & \\
\hline & Moderate & 22 & $27.2 \%$ & 26 & $36.6 \%$ & 48 & $31.6 \%$ & \\
\hline & Severe & 4 & $4.9 \%$ & 7 & $9.9 \%$ & 11 & $7.2 \%$ & \\
\hline & Very severe & 8 & $9.9 \%$ & 9 & $12.7 \%$ & 17 & $11.2 \%$ & \\
\hline \multirow{5}{*}{ Smile } & Very little & 42 & $44.2 \%$ & 23 & $30.7 \%$ & 65 & $38.2 \%$ & \multirow{5}{*}{0.206} \\
\hline & Little & 7 & $7.4 \%$ & 5 & $6.7 \%$ & 12 & $7.1 \%$ & \\
\hline & Moderate & 23 & $24.2 \%$ & 30 & $40.0 \%$ & 53 & $31.2 \%$ & \\
\hline & Severe & 12 & $12.6 \%$ & 7 & $9.3 \%$ & 19 & $11.2 \%$ & \\
\hline & Very severe & 11 & $11.6 \%$ & 10 & $13.3 \%$ & 21 & $12.4 \%$ & \\
\hline \multirow{5}{*}{ Duties } & Very little & 21 & $31.8 \%$ & 14 & $28.0 \%$ & 35 & $30.2 \%$ & \multirow{5}{*}{0.349} \\
\hline & Little & 10 & $15.2 \%$ & 11 & $22.0 \%$ & 21 & $18.1 \%$ & \\
\hline & Moderate & 14 & $21.2 \%$ & 10 & $20.0 \%$ & 24 & $20.7 \%$ & \\
\hline & Severe & 15 & $22.7 \%$ & 6 & $12.0 \%$ & 21 & $18.1 \%$ & \\
\hline & Very severe & 6 & $9.1 \%$ & 9 & $18.0 \%$ & 15 & $12.9 \%$ & \\
\hline \multirow{5}{*}{ Communication } & Very little & 26 & $37.7 \%$ & 26 & $44.1 \%$ & 52 & $40.6 \%$ & \multirow{5}{*}{0.752} \\
\hline & Little & 20 & $29.0 \%$ & 11 & $18.6 \%$ & 31 & $24.2 \%$ & \\
\hline & Moderate & 12 & $17.4 \%$ & 12 & $20.3 \%$ & 24 & $18.8 \%$ & \\
\hline & Severe & 8 & $11.6 \%$ & 7 & $11.9 \%$ & 15 & $11.7 \%$ & \\
\hline & Very severe & 3 & $4.3 \%$ & 3 & $5.1 \%$ & 6 & $4.7 \%$ & \\
\hline
\end{tabular}

MCP: Mont Carlo exact probability 
Table (3) shows comparison between private and public schools in the (intensity) effect of impact on the eight daily performances, duties and smiling were the most severely affected while speaking and Communication was the least. About $12.9 \%$ of children with impacts on duties and 12.4\% of those on Smiling had very severe impacts, while as regards speaking and Communication very severe intensity was only reported by $4.3 \%, 4.7 \%$ respectively.

A percentage of $40.6 \%$ of children with impacts on communication had a very little level of impact Intensity, there was no statistically significant difference detected by Mont Carlo exact probability test in the intensity effect of impact between public and private school.

\section{DISCUSSION}

The main contribution of this study was to carefully adapt the Child-OIDPQ and to assess its psychometric properties. Up to our knowledge this is the first investigation regarding the effect of quality of life related to oral health and school performance carried out in Egypt using this index, and the second attempt to evaluate the psychometric properties of an Arabic version of the Child-OIDP because the first one was performed in Sudan in (2010) (30).

The Arabic version of the Child-OIDP questionnaire when applied to 11-12year-old Egyptian schoolchildren showed acceptable psychometric properties and it is considered a valid, reliable and practical inventory for use in this population.

Test-retest reliability which refers to the degree of agreement between two measurements provided an estimation of the degree to which the results are reproducible (31). The Intraclass Correlation Coefficient (ICC) was 0.886 for severity and 0.837 for frequency. The standard alpha coefficient was above the recommended threshold of 0.7 showing that the index is a stable measure. This result is comparable to other validation studies of the Child-OIDP carried in Spain and Italy $(23,25)$.

The internal consistency of the index which refers to the extent to which a measure is consistent within itself (32), was considered comparable to other results obtained when validating the Child-OIDP in other countries like Thailand (24), France (21), England (20) and Spain (23) regarding Cronbach's alpha were 0.82, 0.57, 0.68and 0.58, respectively compared to $0.714,0.703$ in the present study. Since 0.7 is the cut off for adequate consistency (33). Thus this index can be used in public health programs as an indicator of oral health (33).

Regarding the perceived oral problems (figure 2), sensitive tooth, tooth pain, dental caries and tooth color were the most commonly reported oral problems by the participating children. Similar findings were obtained in Brazil, while in France the problems that were reported with highest prevalence were position of teeth and oral ulcer, this difference may arise from different cultural interests of the different communities $(21,22)$.

The prevalence of impacts observed in Egypt was (85.4\%), this was comparable to those found in other countries where the Child-OIDP was adapted and applied: Thailand (89.8\%) (24), France (73.2\%) (21), Brazil (80.7\%) (22) and Italy (94.5\%) (25). However, it was higher than in England (40.4\%) (20), Sudan (54.6\%) (30) and Spain (36.5\%) (23). This could partly be explained by the younger age of the children in the present survey. In this age, children experienced many problems related to dental eruption and mixed dentition. But after 12 year of age, they would move to permanent dentition, a stage whereby their perceptions about health and quality of life may change. Moreover, comparisons of the prevalence and severity of oral impacts between countries are difficult, since the nature and magnitude of impacts could vary among populations with different cultural backgrounds as already shown in adults $(34,35)$.

The performance with the highest frequency impact was "eating" (61.9\%). This is in accordance with results reported in other studies performed in England, Brazil and Italy (20, 22, 25), where sensitive teeth was the most prevalent condition affecting children's quality of life with regard to eating. This result is logical because in this age, when children have any discomfort or sensitivity in their teeth, it will lead to avoidance of eating. Consequently, untreated eating problems in this developing age will affect children's growth and well-being.

The second daily performance affected by oral health conditions was cleaning teeth (46.3\%); with bleeding gums being the responsible cause for that impact. Children who have difficulty in cleaning their teeth because of gum problems are unlikely to achieve good oral hygiene, brushing may lead to bleeding and pain resulting in avoidance of brushing and subsequent worsening of the problem. In addition to its effect on bad breath whish was actually reported by many of them.

Smiling and emotional status were most often affected by tooth color changes, which demonstrate a normal reaction of the children to bad appearance of their teeth specially in this age, where self esteem starts to affect the emotional condition of the child and probably they start to be sensitive to the reaction of their friends and peers. Meanwhile, the least affected performance by oral health issues were speaking and duties, probably because schoolchildren at this young age could not anticipate the size of impairment of speech and relating this to the oral problems, which reflect the unfamiliarity of the children with the available routes for improvement of speaking as a result of deficiency in oral health education and shortage in accessible dental health service.

These finding were also similar to those of the studies using the CPQ11-14 with pedodontic patients where impacts on functional limitations were more common than impacts on emotional and social well-being (36, 37).

Despite the fact that oral impacts were very frequent in this Egyptian child population, they were not severe; almost half of those with impacts had very little or little intensity of impacts.

Both private and public schools students reported the highest impacts severity on duties and the lowest impact severity on communication (table 3 ), although duties had the least prevalence in the eight performances but it was the most severely affected. The prevalence of the impacts of oral health on daily performances increase was inversely associated with the intensity (severe and very severe impacts affect a reduced number of performances while the little ones affect all of the eight activities included in the questionnaire)). This is in accordance with other studies documenting the same trend. $(38,39)$.

One of the limitations of this study is its cross-sectional design, making it difficult to establish the association between causes and effects, Further future research is also needed to examine the sensitivity to change of the Child- 
OIDP in a longitudinal study design. In this sense, the psychometric properties of the index would have been fully evaluated. Another limitation of this research lies in the substitution of some schools which were included in the proportional allocation random sample due to the multiple refusal and negative attitude from the school administrators and parents of some public schools to participate in the study, in addition to, a lot of absenteeism of students of these schools .

In conclusion, the Arabic Child-OIDP showed acceptable psychometric properties and is considered a valid, reliable and practical inventory for use in this population. Although the prevalence of impacts was high, the severity was not; many children had their quality of life affected at low levels. This reveals a need for further longitudinal studies to better understand and interpret OHRQoL measures in children.

\section{CONFLICT OF INTEREST}

No potential conflict of interest relevant to this article was reported.

\section{REFERENCES}

1. D'aquino R, De Rosa A, Lanza V, Tirino V, Laino L, Graziano A. Human mandible bone defect repair by the grafting of dental pulp stem/progenitor cells and collagen sponge biocomplexes. EUR Cell Mater. 2009;18:75-83.

2. Saikia K, Bhattacharya T, Bhuyan S,Talukdar D,Saikia S,Jitesh P. Calcium phosphate ceramics as bone graft substitutes in filling bone tumor defects. Indian J Orthop. 2008;42:169-72.

3. Finkemeier C. Bone grafting and bone-graft substitutes. J Bone Joint Surg Am. 2002;84:454-64.

4. Giannoudis P, Dinopoulos H, Tsiridis E. Bone substitutes: An update. Injury J. 2005;36:20-7.

5. Singh S. Management of infra bony defects in mandibular molars in a patient with generalized aggressive periodontitis using autogenous bone graft from maxillary tuberosity. J Indian SocPeriodontol. 2010;14:53-6.

6. Kim S. Bone grafting using particulate dentin. Key Eng Mater. 2007;342:29-32.

7. Gutwald R. Mesenchymal stem cells and inorganic bovine bone mineral in sinus augmentation: comparison with augmentation by autologous bone in adult sheep. Br J Oral MaxillofacSurg. 2009;6:226-9.

8. Suárez-González D, Barnhart K, Saito E, Vanderby R, Hollister S, Murphy W. Controlled nucleation of hydroxyapatite on alginate scaffolds for stem cell-based bone tissue engineering. JBiomed Mater Res A. 2010;95:222-34.

9. Dolores J, Enrique M, and Nayeli I. Platelet-Rich Plasma Peptides: Key for Regeneration. Inter J Peptid. 2012;20:10-5

10. Lucarelli E, Beretta R, Dozza B, Tazzari P, O’Connell S, Ricci F, et al. A recently developed bifacial platelet- rich fibrin matrix.Eur Cell Mater. 2010;20:13-23.

11. Choukroun J, Diss A, Simonpieri A, Girard MO, Schoeffler C. Platelet-rich fibrin (PRF): a secondgeneration platelet concentrate. Part IV: clinical effects on tissue healing. Oral Surg Oral Med Oral Pathol Oral RadiolEndod. 2006;101:56-60.

12. Kiran N, Mukunda K, Tilak TN. PlateletConcentrates. J Dent SciRes. 2011;2:50-61.
13. Sunitha R, Munirathnam N. Platelet-rich fibrin: evolution of a second-generation platelet concentrate. Indian J Dent Res. 2008;19:42-6.

14. Ambica K, Sarika C, Sangeeta T, Mahesh V. Endodontic management of single rooted immature mandibular second molar with single canal using MTA and platelet-rich fibrin membrane barrier: A case report. J ClinExp Dent. 2011;3:487-90.

15. Dohan D, Choukroun J, Diss A, Dohan S. Platelet-rich fibrin (PRF): a second-generation platelet concentrate. Part I: technological concepts and evolution. Oral Surg Oral Med Oral Pathol Oral RadiolEndod. 2006;101:37-44.

16. Rodella LF, Favero G, Boninsegna R, Buffoli B, Labanca M, Scari G, et al. Growth factors, CD34 positive cells, and fibrin network analysis in concentrated growth factors fraction. Microsc Res Tech. 2011;74:772-7.

17. Marx RE, Carlson ER, Eichstaedt RM, Schimmele SR, Strauss JE, Georgeff KR. Platelet-rich plasma: Growth factor enhancement for bone grafts. Oral Surg Oral Med Oral Pathol Oral RadiolEndod. 1998;85:638-46.

18. Bashkar SN. Orban' oral histology and embryology. 11th ed. St. Louis, Baltimore, Boston, Chicago, London, Philadelphia, Sydney, Toronto: Mosby; 1990. pp 365, 33941,349-50,470.

19. Werner S, Grose R. Regulation of wound healing by growth factors and cytokines. Physiol Rev. 2003;83:83570.

20.Périssé J, de Bérail A, Lauwers F, Lopez R. Interest of Mineralized Plasmatic Matrix in Secondary Autogenous Bone Graft for the Treatment of Alveolar Clefts. J Craniofac Surg. 2015;26:2148-51.

21. EL Moheb M. The use of growth factors fibrin network to enhance architecture, mechanical and biological aspect of the graft particles. Int J Pre Clin Dent Res. 2014;23:41-4.

22. Mazzoni L, Périssé J. Apports de la microscopie électronique à balayage pour la Matrice Plasmatique Minéralisée. La Lettre de la Stomatologie 2011;51:14-21.

23. Carleton HM, Drury RAB, Wallington EA. Carleton histological technique: Oxford University Press, USA;1980.

24. Eriskan EF, Axelrod DW, Melsen F. Bone histomorphometry. New York: Raven Press; 1994. p 3-12.

25. Ferreira T, Rasband W. Image J user guide. IJI 46r NatlInst Health, Bethesda, MD 2012.

26. Kirkpatric LA, Feeney BC.A simple guide to IBM SPSS: for version 20.0: Nelson Education; 2012.

27. Lee HJ, Choi BH, Jung JH, Zhu SJ, Lee SH, Huh JY,et al. Maxillary sinus floor augmentation using autogenous bone grafts and platelet-enriched fibrin glue with simultaneous implant placement. Oral Surg Oral Med Oral Pathol Oral RadiolEndod. 2007;103:329-33.

28. DohanEhrenfest DM, Bielecki T, Jimbo R, Barbé G, Del Corso M, Inchingolo F,et al. Do the fibrin architecture and leukocyte content influence the growth factor release of platelet concentrates? An evidence-based answer comparing a pure platelet-rich plasma (P-PRP) gel and a leukocyte-and platelet-rich fibrin (L-PRF). Curr Pharm Biotechnol. 2012;13:1145-52.

29. Perisse J, Alami HB, Vassalaky LM, Caveriviere P, Betito M, Marchou M. Aspect clinique et histologique des Matrices Plasmatiques Minéralisées (MPM). Revue d'implantologie. 2012:23-5. 